\title{
Ensaio Sobre as Relações Horizontais: Indagações Sobre a Função do Outro
}

An Essay on Horizontal Relationships: Enquiries
About the Function of the Other

Ensayo Sobre las Relaciones Horizontales: Indagaciones Sobre la Función del Otro
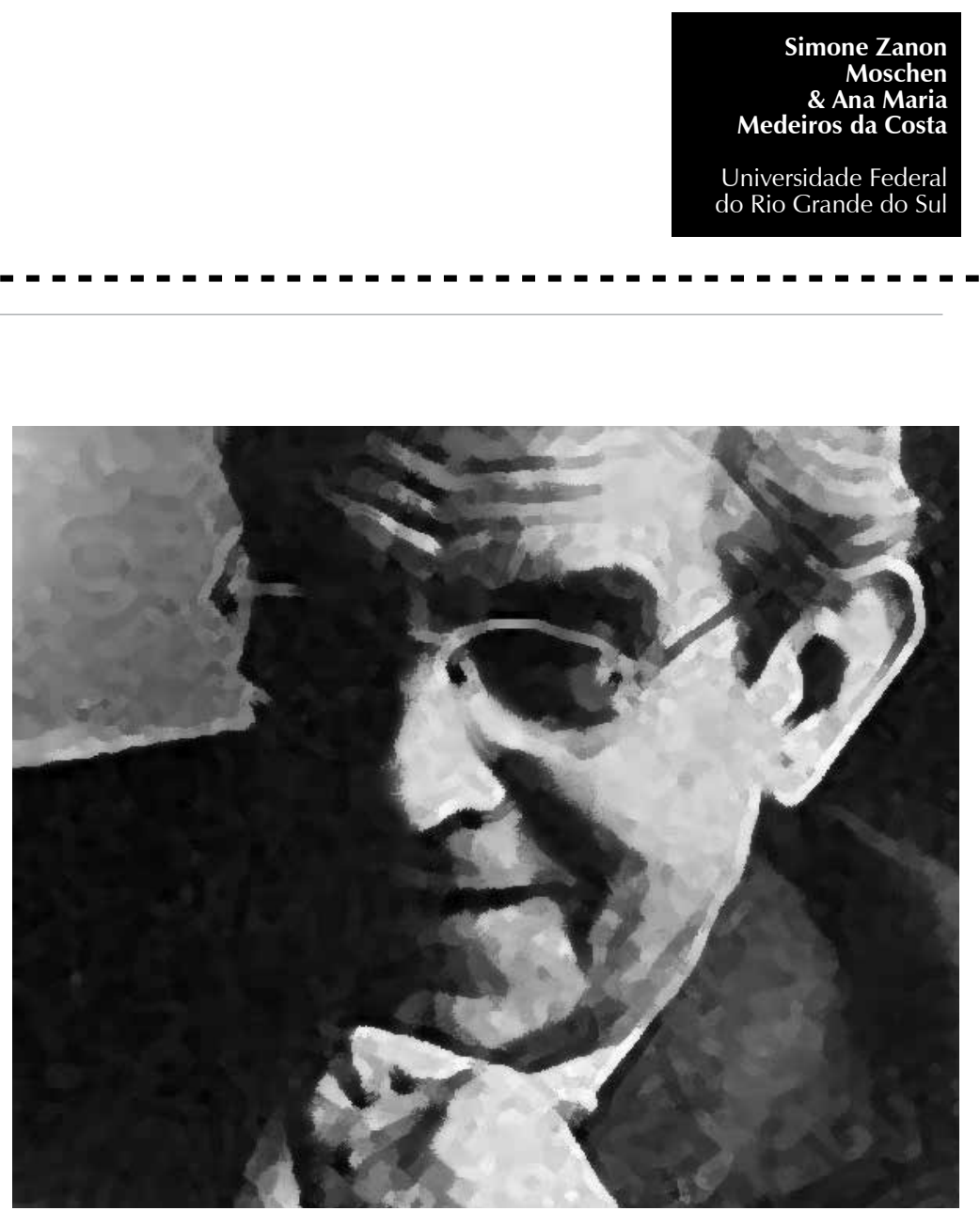
Resumo: No texto Agressividade em Psicanálise (1948), Lacan vai percorrer os meandros da estruturação psíquica, partindo do Estádio do Espelho e da constituição do eu ideal como formação primeira a defender o sujeito do iminente despedaçamento corporal para ir rumo ao Édipo, estrutura ternária capaz de produzir uma fenda nessa imagem primordial totalizada, totalidade que, quando ameaçada, encontra por parte do sujeito uma resposta sempre agressiva. A constituição de um ideal do eu, fruto da passagem edípica, alerta-nos Lacan, tem uma função apaziguadora, capaz de inscrever a distância necessária a uma assunção afetiva do próximo. Paradoxalmente, é a inscrição de uma distância que torna possível a experiência da proximidade, sem que o sujeito se veja assolado por sentimentos de invasão e de aniquilamento. O presente trabalho tem como horizonte indagar o lugar do outro - como parceiro identificatório - tomando como fio dos questionamentos as possibilidades que o compartilhamento da vida pode trazer e o mal-estar que dele pode decantar. Trabalharemos com a proposta de que é no compartilhamento permitido pelo encontro com o semelhante que algo da perda, necessária à emergência do sujeito, ganha consistência, mesmo que transitória, o que dá às relações horizontais uma função que transcende a da rivalização imaginária.

Palavras-chave: Psicanálise. Imaginário. Identificação (Psicanálise). Outro.

Abstract: In the text Aggressivity in Psychoanalysis (1948), Lacan deals with the meanders of psychic structuring, from the Mirror Stage and the constitution of the ideal-I as the first formation to defend the subject from imminent corporal shattering to the Oedipus, ternary structure which is capable of producing a gap in this primordial totalized image, totality which, when threatened, always finds an aggressive response by the subject. The constitution of an I-ideal, outcome of the oedipal passage, as Lacan tells us, has a pacifying function, capable of inscribing the necessary distance to an affective assumption of the fellow man. Paradoxically, it's the inscription of a distance which makes the experience of proximity possible, avoiding the devastation of the subject by feelings of invasion and annihilation. This text has as objective inquiring the position of the other - as identificatory partner - taking the possibilities that the sharing of life can bring and the uneasiness that can decant from it as line of questioning. We'll work with the proposition that it's in the commonality, which is allowed by the encounter with the fellow creature, that something of the loss, which is necessary to the emergence of the subject, gains consistency, even if transitory, which gives to horizontal relationships a function that transcends that of imaginary rivalization.

Keywords: Psychoanalysis. Imaginary. Identification (Psychoanalisis). Other.

Resumen: En el texto La Agresividad en Psicoanálisis (1948), Lacan va a recorrer los meandros de la estructuración psíquica, partiendo del Estadio del Espejo y de la constitución del yo ideal como formación primera a defender al sujeto del inminente despedazamiento corporal, para ir hacia el Édipo, estructura ternaria - capaz de producir una hendidura en esta imagen primordial totalizada; totalidad que, cuando se amenaza, encuentra por parte del sujeto una respuesta siempre agresiva. La constitución de un ideal del yo, fruto del pasaje edípico, nos alerta Lacan, tiene una función apaciguadora, capaz de inscribir la distancia necesaria a una asunción afectiva del prójimo. Paradójicamente, es la inscripción de una distancia que vuelve posible la experiencia de proximidad, sin que se vea asolado el sujeto por sentimientos de invasión y aniquilamiento. El presente trabajo tiene como horizonte indagar el lugar del otro - en tanto partenaire identificatorio -, tomando como hilo de los cuestionamientos las posibilidades que puede traer la compartición de la vida y el malestar que de él puede decantarse. Trabajaremos con la propuesta de que es en la compartición permitida por el encuentro con el semejante que algo de la pérdida, necesaria a la emergencia do sujeto, gana consistencia, aunque transitoria, lo que da a las relaciones horizontales una función que trasciende la de la rivalización imaginaria.

Palabras clave: Psicoanálisis. Imaginario. Identificación (Psicoanálisis). Otro.

Em 1948, no artigo Agressividade em

Psicanálise, Lacan percorre os meandros da estruturação psíquica. Partindo do Estádio do Espelho e da constituição do eu ideal como formação primeira a defender o sujeito do iminente despedaçamento corporal, ele indaga as possibilidades de estabelecimento de relações horizontais que o Édipo cifra. Nesse texto, o acento recai sobre a dimensão de corte inscrita pela estrutura edípica, estrutura essa capaz de produzir uma fenda na imagem totalizada assumida pelo pequeno ser por obra de sua tramitação pelo Estádio do Espelho. A constituição de um ideal do eu, fruto da passagem edípica, alerta-nos Lacan,

tem uma função apaziguadora... (...) A identificação edipiana é aquela através da qual o sujeito transcende a agressividade 
constitutiva da primeira individuação subjetiva. Insistimos em outra ocasião no passo que ela constitui na instauração dessa distância pela qual, com sentimentos da ordem do respeito, realiza-se toda uma assunção afetiva do próximo (1948/1998, pp.119-120)

A constituição de um ideal do eu, fruto da passagem edípica, segundo Lacan, tem uma função apaziguadora, capaz de inscrever a distância necessária a uma assunção afetiva do próximo. Paradoxalmente, é a inscrição de uma distância que torna possível a experiência da proximidade sem que o sujeito se veja assolado por sentimentos de invasão e de aniquilamento. Em tempos em que a solidão constitui queixa recorrente nos consultórios e tema de debate na mídia, gostaríamos, com este trabalho, de percorrer alguns textos de Freud e Lacan que nos possibilitam destacar elementos para pensar na função do outro. Queremos refletir sobre as possibilidades que se abrem com o laço ao próximo bem como sobre o mal-estar que sua presença pode ensejar, e, para tanto, iremos percorrer os movimentos paradoxais que se situam na base da relação do sujeito ao que poderíamos nomear de seu fora. Tomaremos, desta feita, o outro em duas diferentes camadas: em uma posição vertical, quando se apresenta como o próximo que socorre, ou como outro que encarna o Outro Primordial, e em uma posição horizontal, quando se apresenta como irmão, como outro que encarna o que Kehl (2000) denomina função fraterna.

\section{O outro em condição vertical}

Em uma viagem de trem de Berlim a Viena, depois de uma visita ao amigo Fliess, Freud começa a escrever o texto que viria a chamarse Projeto para uma Psicologia Científica. Esse artigo, escrito no outono de 1895, foi, logo após sua escrita, abandonado por seu autor, que o considerava insuficiente em relação às questões que buscava desdobrar. É interessante que, à parte o desconforto de Freud com esse texto, encontramos nele colocados em relação elementos que retornarão sob a forma de diferentes equações ao longo da obra freudiana. No Projeto, encontram-se articulados: desamparo, próximo e o que Freud chama de motivos morais.

Nas formulações freudianas de 1895, o aparelho psíquico é considerado capaz de suportar certa quantidade de energia circulante; o aumento dessa energia, para além desse limiar, dispara no pequeno ser a necessidade de produzir uma descarga que só é possível de ser levada adiante por "uma alteração no mundo externo". Essa alteração, dirá Freud,

se efetua por ajuda alheia quando a atenção de uma pessoa experiente é voltada para um estado infantil por descarga através da via de alteração interna - por exemplo, o grito da criança. Essa via de descarga adquire assim a importantíssima função secundária da comunicação, e o desamparo inicial dos seres humanos é a fonte primordial de todos os motivos morais (1895/ 1976a, p. 336)

O pequeno ser, diante da premência da necessidade de dar vazão a uma tensão, que em seu aumento desmedido pode macular o aparelho psíquico, grita a sua impossibilidade de sozinho encontrar uma solução. O grito do infans é escutado pelo "próximo que socorre" como apelo e, então, respondido nesse diapasão. Os modos que o próximo engendra para responder ao apelo do pequeno ser carregam em si toda a herança simbólica construída ao longo de gerações e depositada nos gestos e nas palavras que buscam abrir passagem à energia acumulada no interior do aparelho. É porque o pequeno já nasce na urgência da presença de um outro, capaz de atualizar os desígnios do Outro, que Freud 
Para Le Pouliche† (1996), o

paradigmático esgotamento da sensação de satisfação produzido pela amamentação e o grito capaz de restabelecer a sensação de plenitude constituem os tempos necessários para que o fora e o objeto tenham lugar. nos diz que temos no desamparo a fonte de todos os motivos morais, como modos, historicamente constituídos, que regulam a circulação social. É a prematuridade do rebento humano que abre espaço para a transmissão dos modos construídos de operar a satisfação dos clamores pulsionais. É também essa prematuridade que inscreve a necessidade de que, para a sobrevivência do infans, acorra uma "ajuda alheia", um outro que socorre, capaz de adotá-lo e de ler em seu grito um apelo à presença e ao cuidado.

A equação traçada em 1895 é retomada por Freud 35 anos depois, em Mal-Estar na Cultura. Mal-estar, unbehagen, nos dirá Márcio Seligman-Silva, no prefácio a sua recente tradução do texto freudiano, remete a "uma fragilidade, a uma falta de abrigo, a estar desprotegido" (2010/1930, p.25). É dos modos de desdobrar o desamparo que caracteriza o homem que Freud se ocupa nessa investigação.

No início do texto, Freud nos convida para a interlocução com um amigo que teria lido seu artigo O Futuro de uma Ilusão (1927/1976e), ao qual gostaria de agregar uma contribuição: em seu modo de ver, Freud deveria melhor explorar a fonte do sentimento de religiosidade abordado naquele texto, fonte essa que o interlocutor freudiano define como um sentimento de “'eternidade', o sentimento como de algo sem limites, sem barreiras, 'oceânico', por assim dizer. (...) um sentimento de união indissolúvel, de pertencimento ao todo do mundo exterior" (Freud, 1930/2010, p. 42). A indagação proposta pelo amigo dá oportunidade a Freud de recolocar o trabalho em torno do sentimento que temos acerca do eu como unidade autônoma e delimitada. Contrapondo a ideia de um eu imaginado como uma esfera, Freud vai nos alertar para os prolongamentos de referida instância, tanto na direção de um suposto "interior", a saber, em direção ao Isso, quanto na direção de um suposto "exterior", a saber, aos objetos pelos quais se esteja apaixonado. No dizer freudiano, o eu é absolutamente sujeito a perturbações de suas fronteiras, imiscuindose nas searas do Isso ou amalgamando-se ao objeto de sua paixão.

É nesse ponto que vemos reaparecer a tese esboçada no Projeto. Freud retoma a proposição de que o eu não se distingue do exterior em seus primórdios, traçando, na origem, uma linha de continuidade sem fraturas com o fora. É pela pulsação da presença do outro, registrada pelo pequeno ser através da intermitente presença/ausência daquilo com que este acode aos seus apelos - o seio materno que se presentifica como consequência dos gritos do bebê para, na sequência, se ausentar -; é por essa pulsação que o eu começa a distinguir-se do não-eu. "Assim se opõe ao eu, pela primeira vez, um 'objeto', algo que se encontra fora e que somente mediante uma ação específica é forçado a aparecer" (1895/1976, p.46).

Para Le Poulichet (1996), o paradigmático esgotamento da sensação de satisfação produzido pela amamentação e o grito capaz de restabelecer a sensação de plenitude constituem os tempos necessários para que o fora e o objeto tenham lugar. A sequência esgotamento, interrupção, ação e restabelecimento da satisfação constitui uma operação que tem como efeito a abertura de uma lacuna em que virá alojar-se o objeto. Esse processo faz advir a presença sob um fundo de ausência e, em consequência, a oposição simbólica entre dentro/fora. É do pulsar presença-ausência-presença que se registrarão a tridimensionalidade do espaço e a irreversibilidade do tempo, experiências 
1 A tradução brasileira aqui utilizada é a da Editora Imago. Nela os termos verneinung e verdrängung são traduzidos, respectivamente, por negativa e repressão.

O presente texto mantém a tradução referida nas citações.

Quando se tratar de uma elaboração própria dos conceitos,

utilizarei a palavra

denegação para traduzir verneinung e o vocábulo recalque para traduzir verdrängung.

2 O exame do conceito de denegação deixa ver a existência de um paradoxo interno, a saber, levantamento e manutenção do recalque em um mesmo movimento. A ideia de um pensamento sustentado por operações, à primeira vista, incompatíveis, parece ser recorrente no exame das questões relativas ao sujeito. ausentes em um momento mítico no qual figurava a planitude bidimensional entre eu e outro e em que a não inscrição do intervalo fazia o tempo tramitar em um eterno hoje.

Em Mal-estar na Civilização, Freud vai apontar também outra fonte para o estabelecimento de uma mínima diferença entre o eu e o não-eu.

\begin{abstract}
Um outro estímulo para que o eu se desprenda da massa de sensações, ou seja, para que reconheça um 'fora', um mundo externo, é dado pelas freqüentes, variadas e inevitáveis sensações de dor e prazer, que o princípio do prazer, senhor absoluto, ordena suprimir e evitar (1930/2010)
\end{abstract}

Ao referir o trabalho do princípio do prazer como agenciador de uma mínima distinção entre eu e outro, Freud retoma algo que havia estabelecido cerca de cinco anos.

Em 1924, Freud havia publicado um artigo denominado A Negação (Die Verneinung). Trata-se de um texto curto que, embora bastante tardio em relação aos chamados Escritos sobre a Técnica, que datam de 19141915, foi incluído, por muitos comentaristas, nesse conjunto de artigos. Isso talvez se deva ao fato de que, ao iniciar o trabalho, Freud chama a atenção para um fenômeno bastante comum na clínica, a saber, a inscrição na fala do paciente de algo que ele supõe ser a ideia que ao analista ocorre naquele momento para, logo a seguir, desmenti-la. Exemplifica o autor: "'O senhor pergunta quem pode ser essa pessoa no sonho. Não é minha mãe'. Emendamos isso para: 'É a mãe

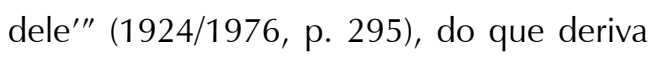
a importante dica clínica de desprezar a negação que acompanha o pensamento do paciente para dele reter apenas o conteúdo. Afora o que neste artigo possa referir-se ao manejo da técnica, algo vai interessar-nos, e muito, se estamos empenhados em perseguir o lugar que o fora/outro representa no advento do sujeito. Em primeiro lugar, vemos Freud abordar aqui o tema da inteligência. $\mathrm{E}$ como a pergunta sobre a negação o conduz a isso?

Ao examinar esse recorrente modo de o sujeito se apresentar na análise sob a forma da negação, o autor propõe:

o conteúdo de uma imagem ou idéia reprimida pode abrir caminho até a consciência, com a condição de que seja negado. A negativa constitui um modo de tomar conhecimento do que está reprimido; com efeito, já é uma suspensão da repressão, embora não, naturalmente, uma aceitação do que está reprimido ${ }^{1}$. Podemos ver como, aqui, a função intelectual está separada do processo afetivo (1924/1976, p. 296)

Freud faz ver, ao descrever o mecanismo da negação, que o conteúdo de uma ideia que até então habitava o inconsciente pode emergir na consciência, desde que antecedida por uma negação, deixando, assim, ao sujeito, uma certa parcela de liberdade para com esse conteúdo ideativo operar, para com ele alimentar a sua capacidade de conhecer e de pensar; porém, isso se faz à custa de que tal conteúdo não venha a ligar-se novamente ao afeto cuja incompatibilidade com a consciência fez com que recaísse sobre tal ideia o mecanismo do recalque. Temos, então, algo como um levantamento do recalque sem o reconhecimento, por parte do sujeito, de que aquilo que emergiu seja próprio dele, o que acarreta, em certa medida, a manutenção do recalcamento - operam, ao mesmo tempo, suspensão e manutenção ${ }^{2}$ "Assim, com o auxílio do símbolo da negativa, o pensar se liberta das restrições da repressão e se enriquece com material indispensável ao seu funcionamento correto" (1924/1976, p. 297). Ao apresentar a possibilidade de o sujeito, 
3 Vale aqui lembrar uma passagem do texto de Freud Os Instintos e suas Vicissitudes (As Pulsões e seus Destinos):

"Originalmente, no próprio começo da vida mental, o ego é catexizado com as pulsões, sendo, até certo ponto, capaz de satisfazê-las em

si mesmo. (...) Nessa ocasião, o mundo externo não é catexizado com interesse. (...) Na medida em que o ego é autoerótico, não necessita do mundo externo, mas, em conseqüência das experiências sofridas pelas pulsões de autopreservação, ele adquire objetos daquele mundo, e apesar de tudo, não pode evitar sentir como desagradáveis, por algum tempo, estímulos pulsionais internos. Sob o domínio do princípio do prazer ocorre agora um desenvolvimento ulterior no ego. Na medida em que os objetos que Ihes são apresentados constituem fontes de prazer, ele os toma para si próprio (...), e, por outro lado, expele o que quer que dentro de si mesmo se torne uma causa de desprazer " (1915/1976, p.157). através de um juízo intelectual, negar o conteúdo de um pensamento, Freud vai procurar percorrer as origens dessa prerrogativa. É então que o artigo se torna mais interessante, na medida em que, nesse momento, propõe situar a gênese do juízo em uma primeira cisão - mítica - que produziria o que seria da ordem do eu e aquilo que se referiria ao não-eu. O interrogante centrase, então, em delimitar as condições que permitem a um sujeito dizer: "Isso é meu", "Isso sou eu", e "Isso é do outro" ou "É o outro", ou seja, como se produz uma primeira experiência do dentro e do fora? Como se cinde o sentimento oceânico no qual vivia mergulhado o pequeno ser? Vemos aqui aparecer a referência à negação como condição de possibilidade de uma primeira inscrição dessa experiência.

Freud vai situar como originário um tempo mítico em que, sob a ação do eu-prazer, o sujeito é retirado de uma planitude inicial entre ele e seu entorno. É por intermédio de uma operação que situa como lhe sendo exterior tudo que por ele é sentido como mau, como produtor de desconforto, e como interior tudo que é sentido como bom, tudo que lhe confere prazer, é por intermédio dessa operação que uma primeira cisão se inscreve. Trata-se de um momento primordial no qual vemos atuar o eu-prazer a incorporar o que lhe dá prazer e a expulsar o que lhe confere desprazer.

A condição do sujeito de se referir a um fora como distinto dele próprio é efeito de uma primeira operação de expulsão capaz de produzir essas duas instâncias em uma certa tensão - dentro/fora; eu/não-eu. De início, é preciso imaginar um tempo em que ela não existia. As origens desse mecanismo, que Freud chamou de juízo de atribuição, ou seja, a capacidade de o sujeito decidir sobre as características de algo, inscreve-se a partir de uma expulsão que funda duas instâncias em tensão, em um momento segundo em relação ao que seria o da pura unidade, em que ainda não se verificaria a existência de um eu e de um não-eu³. A negação (expulsão) aparece como subsequente a esse momento inaugural de continuidade.

Conforme Hippolyte: "O importante é que, no 'começo', dá na mesma, é indiferente saber se há ou não há. Há" (1998, p. 899). Se no começo temos, como vimos, uma unidade mítica, a questão acerca da existência ou não de uma representação na realidade não se coloca para o sujeito - se é que podemos conferir-lhe essa denominação - , pelo simples fato de não haver algo como uma realidade interior em distinção a uma realidade exterior. Temos um contínuo, sem rupturas. É no desdobramento do eu-prazer, anteriormente mencionado, fruto de uma primeira expulsão que permitiu criar um dentro e um fora, sendo o primeiro identificado às coisas que essa instância introjetou e o segundo àquilo que ela expulsou, que se desenhará o eu-realidade, instância responsável por certificar-se de que algo que ora se encontra no interior do eu, como representação, pode ser reencontrado na realidade. É aí que podemos localizar a origem da disjunção entre o que é subjetivo e, portanto, existe no interior do sujeito, mas não pode ser reencontrado em seu exterior, e o que é objetivo e tem realidade assegurada em ambos os lugares: a esse atributo Freud nomeará juízo de existência.

Ao retomar a afirmação de Freud de que a função do juízo só é possível a partir da criação do símbolo da negação, Hyppolite questiona: "Por que Freud não nos diz: 'o funcionamento do juízo se torna possível pela afirmação?' É que a negação vai desempenhar um papel não de tendência para a destruição, 
nem tampouco no interior de uma forma de juízo, mas de atitude fundamental de simbolicidade explícita" (1988, p.900). É na criação do símbolo de negação, na sua inscrição psíquica, que vemos desenhar-se a origem do simbólico, instância propriamente humana, dotada do poder de criação. Não é à toa, então, que justamente no texto em que Freud vai examinar a negação, ele fale sobre a inteligência, sobre sua separação do afeto. Conforme Lacan: "realmente parece, ao ouvir Freud hoje, que é a hiância de um vazio que constitui o primeiro passo de todo o seu movimento dialético" (1953-1954/1998, p. 394). É a partir de uma primeira expulsão, de uma primeira negação, que se inscreve a pulsação ausência/presença, suporte dos deslocamentos simbólicos.

Mas retomemos a formulação freudiana no Mal-estar na Cultura, que nos permite a reprodução de uma longa passagem:

Originalmente, o eu contém tudo, mais tarde, ele segrega de si um mundo exterior. O nosso atual sentimento do eu, portanto, é apenas um resíduo minguado de um sentimento de grande abrangência - na verdade, um sentimento que abrangia tudo e correspondia a uma íntima ligação do eu com o ambiente. Se nos for permitido supor que esse sentimento primário do eu tenha ficado conservado - em maior ou menor medida - na vida psíquica de muitas pessoas, então ele seria uma espécie de contraparte do sentimento do eu, delimitado de modo mais restrito e mais claro, próprio da maturidade, e os conteúdos ideativos correspondentes a esse sentimento primário seriam justamente os de uma ausência de limites e de uma ligação com o universo, os mesmos que meu amigo usou para explicar o sentimento 'oceânico'. Temos, porém, o direito de supor a sobrevivência do originário ao lado do posterior que dele se formou? (1930/2010, p.48)

À pergunta sobre a pertinência da hipótese sobre a sobrevivência do originário ao lado daquilo que posteriormente dele se formou,
Freud responde afirmativamente. De algum modo ele nos situa frente ao fato de que as fronteiras que delimitam um externo são instáveis, e, mais do que isso, precisam em certos momentos ser restabelecidas, não por obra de uma reedição das operações aqui descritas como míticas, mas pelo testemunho de um outro capaz de assegurar a consistência da perda que está na origem do sujeito. Esse outro, então, assume, frente ao sujeito, um lugar contrastante, quase paradoxal; pode apresentar-se como fonte de paixão e, por causa disso, ameaçar a consistência das fronteiras entre o eu e o outro, inundando o sujeito do dito sentimento oceânico, ou pode apresentar-se como opacidade e resistência a qualquer reincorporação, opacidade que se sustenta na intermitência e não controle de sua presença, na pulsação com que aparece e desaparece para o sujeito. É dessa opacidade que o sujeito recolhe efeitos de testemunho sobre a consistência da perda de uma unidade entre o organismo e o mundo, perda que marca sua emergência.

\section{O outro em condição horizontal}

No livro intitulado O Próximo (2005), Isidoro Vegh procura sustentar a tese de que o outro - com minúscula - ocupa lugar estruturante no advento do sujeito, guardando em si a ambiguidade de poder apresentar-se como lugar de toda alienação possível, e também como lugar que dá testemunho de uma separação. Em seu trabalho, o autor retoma um pequeno trecho da obra de Levinas filósofo de quem guarda diferenças, mas cuja produção o faz trabalhar. Destaca ele do escrito de Lévinas : "O pensamento começa com a possibilidade de conceber uma liberdade exterior à minha" (Lévinas como citado em Vegh, 2005, p.28). É interessante isto que se cruza no dito do filósofo: pensamento e exterioridade, cuja proposição nos reenvia 
ao trabalho de Freud com a Negação que acima relembramos, pensamento e exterioridade ao qual agregaríamos, com Freud, desamparo. Como vimos,

se não se constitui um não-eu, um não-sujeito parte da estrutura, não há possibilidade de uma primeira inscrição do sujeito. A expulsão precede o primeiro traço que se inscreve. Daí a radicalidade extrema do reconhecimento dessa vigência do outro como condição e parte da estrutura do sujeito (Vegh, 2005, p. 28)

Em um texto de 1938 - escrito cerca dez anos antes do Estádio do Espelho -, Lacan vai trabalhar com o que à época chamava de complexos familiares: um conjunto de reações que desempenha um papel organizador no desenvolvimento psíquico. Os complexos trabalhados por ele são: do desmame, de intrusão e de Édipo. Concentremo-nos no segundo. Lacan está interessado, nesse trabalho, em sustentar o lugar do irmão na estruturação psíquica, em pensar sobre os efeitos, para o sujeito, quando ele realiza a presença de um outro, um irmão. Deve-se pontuar que Lacan situará no trabalho gerado pelo ciúme infantil a "gênese da sociabilidade, por aí, do próprio conhecimento - (novamente o exterior e o pensamento se cruzando - como em Freud e Lévinas) Digamos que o ponto crítico revelado por essas pesquisas é que o ciúme, em sua essência, representa não uma rivalidade vital, mas uma identificação mental" (1938/2003, p. 43). Para Lacan, o ciúme não é efeito de uma rivalidade do pequeno em relação ao amor dos pais, mas fruto da identificação do pequeno com o semelhante; o irmão aparece como aquele que pode ameaçar a identidade imaginária da criança operada pela assunção de sua imagem especular. Conforme Kehl,

introduzindo na organização narcísica infantil a confrontação com a máxima semelhança e a inevitável diferença, o irmão força o rompimento da prisão especular daquele que até então se via idêntico a si mesmo - como objeto do desejo materno ou como sujeito identificado ao traço instituído pelo nome do pai, a depender do momento em que o outro faz sua entrada em cena (2000, p.36)

Diante da visão do outro em posição de semelhante, o sujeito, comprometido no ciúme por identificação, encontra duas saídas: ele pode engajar-se em reaver seu lugar na especularidade sustentada pelo amor materno através do empenho na destruição do outro e na recusa do real ou pode acolher algum outro objeto que carregue os vestígios do outro, os vestígios do social. Levado a algum outro objeto, Lacan afirma que

ele o recebe sob a forma característica do conhecimento humano, como objeto comunicável, já que concorrência implica ao mesmo tempo rivalidade e concordância; mas, ao mesmo tempo, ele reconhece o outro com o qual se engaja a luta ou o contrato, em resumo, ele encontra, ao mesmo tempo, o outro e o objeto socializado" (1938/2003, p. 49 grifo nosso)

Dez anos depois, no texto do Estágio do Espelho, Lacan dirá: "esse momento em que se conclui o estádio do espelho inaugura, pela identificação com a imago do semelhante e pelo drama do ciúme primordial (tão bem ressaltado (...) nos fenômenos de transitivismo infantil), a dialética que desde então liga o (eu) a situações socialmente elaboradas" (1948/1998, p. 101). Na porta de saída do Estádio do Espelho, encontramos o semelhante a desestabilizar a imagem ideal assumida pelo sujeito e a sua aposta de poder corresponder a essa imagem. Abre-se uma fenda entre a imagem e o sujeito, e, a esse abalo, ele responde com agressividade, mas também com um empuxo, à identificação. Talvez possamos destacar aqui que toda identificação 
"Lacan enfatiza a relação entre agressividade, semelhante e a estrutura narcísica do eu, que se ergue como fortaleza contra a invasão do outro, ao mesmo tempo em que depende dele para se estruturar" (2000, p.38). comporta um movimento duplo de anulação e de manutenção do outro, anulação do outro pelo traço que lhe é roubado e que agora deverá manter-se fora do domínio daquele, e manutenção do outro pela perpetuação desse traço em si como suporte para o eu. Kehl observa que "Lacan enfatiza a relação entre agressividade, semelhante e a estrutura narcísica do eu, que se ergue como fortaleza contra a invasão do outro, ao mesmo tempo em que depende dele para se estruturar" (2000, p.38). Podemos dizer que é pelo rival que o sujeito tem notícias da perda de seu lugar, mas é também por sua presença, em sua pele, que o desejo adquire maior consistência, na medida em que sua encarnação (na existência do outro) o confirma.

Como nos lembra Ana Costa, o encontro com o semelhante pode dar testemunho, no a posteriori, de uma perda experienciada pelo sujeito. É no compartilhamento permitido por esse encontro que algo da perda ganha consistência, mesmo que transitória. Nas palavras da autora:

É necessário um movimento de inclusão do singular no campo da cultura, e é nesse movimento que podemos encontrar a autorização na função do semelhante, nesse que situa o objeto perdido numa certa condição de um real compartilhado, em relação ao qual cada um pode dar seu testemunho singular. Somente nesse movimento podemos pensar algo da transmissão do inconsciente, na medida em que em relação a essa experiência não há um eu que se autorize num sentido positivado (1998, p.124)

O semelhante, por seu testemunho, confere densidade ao que se constitui como perda e reconstitui o traçado de uma fronteira, sempre móvel e instável, entre o sujeito e o exterior. Se tomarmos o texto freudiano Totem e Tabu (1913/1976), na construção mítica com que ele nos brinda, vemos sublinhada a necessidade, de tempos em tempos, de refazer, de forma ritualística, os atos que permitiram inscrever um corte na posição de inteira sujeição dos irmãos a um pai absoluto - inteira sujeição da qual, paradoxalmente, advinha um amparo absoluto. Freud, a partir dos estudos de Darwin, desenhará os primórdios míticos de uma coletividade sustentada por um referente simbólico cuja consistência se produz devido a um pacto horizontal. O mito freudiano principia com a existência de um pai primevo, senhor absoluto, que tinha acesso a todas as mulheres e a quem tudo era permitido. Esse pai da horda primitiva teria sido assassinado pelos filhos/irmãos que haviam sido expulsos do clã e que, unidos, encontraram as condições de retornar e de cometer o referido ato - o que individualmente não poderiam fazer. Após morto, esse pai teria sido devorado pelos irmãos, que, por causa desse gesto, produziram a identificação com esse que tanto admiravam quanto odiavam. Uma vez deposto o pai de sua posição absoluta, aos irmãos restava instituir um pacto capaz de protegê-los da restauração da ordem recém banida: inscreve-se então na comunidade o tabu do incesto e a necessidade da exogamia - não era possível ter a mulher do pai. Pela inscrição de um não, de uma negatividade, os sujeitos se ordenam em uma coletividade. No mito freudiano, o negativo, representado pelo pai morto alçado à condição simbólica, pela interdição do totem e pela proibição do incesto, coloca-se como marca originária que permite a construção de um coletivo.

Pode-se observar que, de tempos em tempos, Freud supõe a rememoração ritualística do ato que deu fim à horda primitiva. $\mathrm{O}$ ato empreendido pelos irmãos não produz efeitos perenes, ele precisa ser refeito, 
reeditado de tempos em tempos. Em uma comemoração totêmica, os irmãos lembramse do ato que cometeram e elaboram a culpa que esse ato gerou, culpa que podemos tomar, em certa medida, de acordo com Kehl, como "desejo de uma submissão absoluta sem limites, portanto, impossível, ao Outro" (2002, p. 32). Para Freud, a refeição totêmica, que é talvez o mais antigo festival da humanidade, seria assim uma repetição e uma comemoração desse ato memorável e criminoso, que foi o começo de tantas coisas: da organização social, das restrições morais e da religião. De algum modo, o mito freudiano situa no irmão, no semelhante, a rivalidade, não extinguível, mas também a condição de sustentação de uma interdição - como se o irmão se colocasse como suporte de uma memória, como suporte de um limite.

Há algo que nos parece precioso na proposta de Totem e Tabu (1913/1976). Ela reinscreve o desamparo como o ponto a partir do qual se desdobram todos os atos ditos humanos, todos os atos de linguagem. Se o pai da horda primitiva se situava como tirano capaz de doar a vida e a morte, nesse mesmo pai, estava depositada a força de um amparo absoluto - desde que se seguissem os seus preceitos. Uma vez que não se diferisse, estava-se em uma condição de absoluta proteção. O assassinato do pai abre o espaço da diferença, a necessidade da fala, e ressitua o desamparo. Não se está mais sujeito ao um senhor onipotente, e os irmãos devem, gastando muito latim, manter as condições de um pacto que permita situar na semelhança de sua posição frente à Lei a condição do exercício de uma certa diferença. Kehl destaca que "o pai simbólico, representante da Lei (...), é o significante do pacto instituído pelos irmãos, livres e desamparados - e livres porque desamparados - depois do assassinato do tirano, o pai real da horda primitiva" (2002, p.45).

\section{"Ruim com ele, pior sem ele"}

Como consequência dessa miragem originária que nos espreita, somos sempre assolados pelo fascínio da submissão como forma de exorcizar os temores que advém do desamparo. A procura por um pai absoluto e despótico ronda o sujeito. O encontro com essa miragem traz o terrível efeito de suspender o pensamento, com todos os desdobramentos que isso pode trazer. A banalidade do mal prolifera no vazio do pensamento, nas condições nas quais os homens se veem dispensados de pensar. Aí corre um fio que articula nossa retomada do texto freudiano: a produção de um fora, condição de emergência do sujeito - e de sua qualidade pensante - é efeito de uma perda gerada pelo encontro/desencontro com o outro - o outro que se apresenta em sua disparidade como adulto que responde ao grito do pequeno, tomando-o como demanda a ele dirigida; o outro como irmão/rival que encarna a diferença entre a imagem e o sujeito, ou ainda, o outro como semelhante que, por seu testemunho, dá consistência à perda de um amparo absoluto e convida à invenção coletiva de formas de transpor o desamparo que a morte do pai enseja.

É o desamparo que abre a necessidade de uma fabulação pensante e talvez por isso encontremos tão reiteradamente a relação, em Freud, entre a instauração de um fora e a faculdade pensante - apresentada como inteligência e conhecimento. É porque algo de uma perda se operou para instaurar uma cisão originária que o sujeito se vê convocado, com 
os outros, a criar e a recriar as bordas dessa perda. Que essa convocação traga em si o vírus da paranoia já nos alertava Lacan, pois estar com o outro é sempre ver atualizada a miragem de uma sujeição. Mas haveria outro caminho? E o que ele nos reservaria?

Simone Zanon Moschen

Pós-doutora em Psicanálise pela Universidade Estadual do Rio de Janeiro e Professora do curso de Pós-Graduação em Educação e de Pós-Graduação em Psicologia Social e Institucional da Universidade Federal do Rio Grande do Sul, Porto Alegre - RS - Brasil.

E-mail: simonemoschen@gmail.com

\section{Ana Maria Medeiros da Costa}

Pós-doutora pela Université Paris 13 e professora do Curso de Pós-Graduação em Psicanálise da Universidade Estadual do Rio de Janeiro, Rio de Janeiro - RJ - Brasil.

E-mail: ammcosta@terra.com.br

Endereço para envio de correspondência:

Rua Tomás Gonzaga, 430 / 08. CEP: 91340-480. Porto Alegre, RS.

Recebido 24/09/2012, Aprovado 16/10/2013. 


\section{Referências}

Costa, A. (1998). A ficção do si mesmo. Rio de Janeiro : Companhia de Freud.

Freud, S. (1976a). Projeto para uma psicologia científica. In Edição Standard Brasileira das Obras Completas de Sigmund Freud ( 2 a ed.). Rio de Janeiro: Imago. (Trabalho original publicado em 1895).

Freud, S. (1976b). Totem e tabu. In Edição Standard Brasileira das Obras Completas de Sigmund Freud (2a ed.). Rio de Janeiro: Imago. (Trabalho original publicado em 1913).

Freud, S. (1976c). Os instintos e suas vicissitudes. In Edição Standard Brasileira das Obras Completas de Sigmund Freud (2a ed.). Rio de Janeiro: Imago (Trabalho original publicado em 1915).

Freud, S. (1976d). A negativa. In Edição Standard Brasileira das Obras Completas de Sigmund Freud (2a ed.). Rio de Janeiro: Imago. (Trabalho original publicado em 1924).

Freud, S. (1976e). O futuro de uma ilusão. In Edição Standard Brasileira das Obras Completas de Sigmund Freud (2a ed.). Rio de Janeiro: Imago. (Trabalho original publicado em 1927).

Freud, S. (2010). O mal-estar na cultura. Porto Alegre: L\&PM Editores (Trabalho original publicado em 1930).

Hyppolite, J. (1998). Comentário falado sobre a "Verneinung" de Freud. In J. Lacan, Escritos (pp. 893-902). Rio de Janeiro: Zahar (Trabalho original publicado em 1966).

Kehl, M. R. (2000). A função fraterna. Rio de Janeiro: Relume Dumará.
Kehl, M. R. (2002). Sobre ética e psicanálise. São Paulo: Companhia das Letras.

Lacan, J. (1998). A agressividade em psicanálise. In Escritos (pp. 104-126). Rio de Janeiro: Zahar (Trabalho original publicado em 1948).

Lacan, J. (1998). O estádio do espelho como formador da função do eu. In J. Lacan. Escritos (pp. 96-103). Rio de Janeiro: Zahar (Trabalho original publicado em 1949).

Lacan, J. (1998). Introdução ao comentário de Jean Hyppolite sobre a "Verneinung" de Freud. In J. Lacan. Escritos (pp. 370382). Rio de Janeiro: Zahar (Trabalho original publicado em 1953-1954).

Lacan, J. (1998). Resposta ao comentário de Jean Hyppolite sobre a "Verneinung" de Freud. In J. Lacan. Escritos (pp. 383-401). Rio de Janeiro: Zahar (Trabalho original publicado em 1966).

Le Poulichet, S. (1996). O tempo na psicanálise. Rio de Janeiro: Zahar.

Seligman-Silva, M. (2010). Prefácio. In S. Freud. O mal-estar na cultura. Porto Alegre: L\&PM Editores (Trabalho original publicado em 1930).

Vegh, I. (2005). O próximo. Rio de Janeiro: Companhia de Freud. 